\title{
PENSAR A ESTÉTICA DO ENCONTRO INTERSUBJETIVO COMO EXPERIÊNCIA FORMATIVA
}

\section{Rodrigo Avila Colla*}

Resumo: Discute-se a experiência intersubjetiva sensível enquanto dimensão autonomamente formativa. Nessa perspectiva, o encontro estetizado entre sujeitos favorece a criação, por qualquer uma das partes, de alternativas de conhecimentos, de vias de subjetivação e de modos de experienciação que não seriam possíveis não fosse o reconhecimento do outro enquanto legítimo $e$, ao mesmo tempo, fonte de possibilidades de recriação do eu.

Palavras-chave: Alteridade; Educação Estética; Ética; Ética e Formação; Intersubjetividade.

Resumen: Discute la experiencia intersubjetiva sensible mientras dimensión autonomamente formativa. En esta perspectiva, el encuentro entre sujetos apreciado sensiblemente favorece la creación, por cualquiera de las partes, de alternativas de conocimiento, vías formación de subjetividad y de modos de experimentar que no serían posibles sin el reconocimiento del otro como legítimo $y$, al mismo tiempo, fuente de posibilidades de recreación del yo.

Palabras claves: Alteridad; Educación Estética; Ética; Ética y Formación; Intersubjetividad.

\footnotetext{
* Mestrando do Programa de Pós-graduação em Educação da Pontifícia Universidade Católica do Rio Grande do Sul (PUCRS). Bolsista de mestrado do CNPq. E-mail: rodrigo.a.colla@gmail.com
}

\section{Introdução}

Pretende-se neste artigo pensar o encontro intersubjetivo enquanto experiência estética que contribui com a formação humana, sobretudo, do ponto de vista moral. Entende-se, assim, que a sensibilidade atua como via de acesso ao entendimento mínimo entre os sujeitos que se lançam mutuamente ao encontro, mas, mais do que isso, contribui com a ampliação do horizonte formativo. Nesse sentido, ela torna possível o experienciar dialógico. Por meio dessa premissa se pode refletir acerca da intersubjetividade como experiência de formação para a autonomia, uma vez que o encontro intersubjetivo vivenciado de modo sensível apresenta-se como instância passível de recriação de parâmetros de condutas e de subjetivação.

Com isso, se quer lançar um olhar diverso sobre o a experiência do convívio. Conviver não é apenas tolerar, mas tomar parte num processo de aprendizado constante em que, não

COLLA, Rodrigo Avila. Pensar a estética do encontro intersubjetivo como experiência formativa. Revista Sul-Americana de Filosofia e Educação. Número 21: nov/2013abr/2014, p. 89-103. 
raro, são repensadas as possibilidades de vir a ser $e$ as vias de formação que se apresentam também como fomentadoras de uma moral integrativa. Os sujeitos, nessa perspectiva, de um lado deslizam em direção ao rompimento com o individualismo e constituem uma conduta autônoma que, além de se abrir à criação, não anula a alteridade, de outro exercitam a sensibilidade no ato de vivenciar o encontro enquanto arte subjetivadora e o outro enquanto cocriador.

\section{A Experienciação do/com o Outro}

Nietzsche (2000) há mais de um século já alertava para a necessidade de se formar espíritos livres, libertos da égide da moral, alheando-se a maniqueísmos, elevando-se à sabedoria e libertando-se de uma tradição rija. Esses espíritos livres não se encontrariam acorrentados ao ódio ou ao amor e teceriam seus juízos a partir de afinidades ou animosidades, mas transcenderiam os juízos-em-si para ajuizar-se a si próprios num constante embate existencial consigo e com o derredor em sua complexidade. O espírito livre lançar-se-ia, assim, a estar "em toda parte pene- trando, quase sem temor, nada desprezando, nada perdendo, tudo saboreando, tudo limpando e como que peneirando do que seja acaso [os problemas a enfrentar e destrinçar]" (NIETZSCHE, 2000, p. 14). Lançando mão ainda de todo e qualquer elemento libertador-formador ao seu alcance, o espírito livre afigura-se ao ser capaz de buscar uma aderência sutil e desapegada ao ambiente experienciável, numa absorção de todo seu potencial formador, mas num processo gradativo de absolvição da pena de levar bagagens.

Esse ideal de autoformação presente no argumento do filósofo contempla, sobretudo, a dimensão da experiência $e$ a potencialidade formadora de despir-se de tudo que se é e lançar-se ao mundo como um estrangeiro. No entanto, o que mais interessará discutir aqui dessa essência expecienciadora do espírito livre, embora esse quesito não estivesse tão patente na obra de Nietzsche, é justamente o encontro intersubjetivo e a possibilidade de pensar a própria formação a partir dessa perspectiva sob o ponto de vista estético de uma experiência dessa natureza. Em outras 
palavras, pensar a fluidez da experiência intersubjetiva como uma espécie de exercício de sensitividade, como uma abertura sensível a uma construção de conhecimento estetizada que, na experienciação do outro enquanto outro-possível, ajuda a construir um repertório de possibilidades de ser/sentir/perceber/pensar a experiência em si, a alteridade e o próprio conhecimento. Ao longo deste texto se buscará deixar isso mais claro.

Ao se defrontar com o outro e, consequentemente, com outra realidade, com um olhar diverso sobre ela, o sujeito defronta-se ao mesmo tempo com seu próprio histórico de percepção da realidade que o cerca. Nesse sentido, ele é interpelado de alguma forma por se posicionar sobre o ainda não pensado/sentido. Ao pensar o nunca antes pensado ou cogitá-lo ensaisticamente na experiência de assunção do outro, o sujeito vivencia um duplo encontro: o encontro com o outro e o encontro de siagora consigo-antes. O reconhecimento do outro implicaria, assim, não só o reconhecimento de si próprio enquanto sujeito histórico, mas a sondagem de múltiplas possibilidades de vir a ser.

Para Humberto Maturana (1998) o reconhecimento do outro enquanto legítimo outro na convivência é um ato de amor. Assim, amar pressupõe a aceitação legitima da outra-razão que não será vista como uma inverdade ou um equívoco, mas justamente como outra-verdade $e$, nesse sentido, $\mathrm{o}$ ato de reconhecer $\mathrm{o}$ outro exclui o amor ou o ódio entendidos sob o prisma romântico $e$ instaura uma abertura à empatia e, sucessivamente, um gosto pela experienciação do choque dos apostoscomplementares não para a ruptura, mas para a aglutinação formadora.

Nesse viés, esse ato de aceitação não se trata de um reconhecimento refletido, negativo-positivo, como reconhecer o branco no preto ou vice-versa, mas aproxima-se do que Hegel (apud FLICKINGER, 2011) considera ser o ideal de reconhecimento na relação social $e$, em certa medida, até o transcende. $\mathrm{O}$ reconhecimento da autenticidade da outra-verdade possível e, por consequência, a legitimidade do outro sujeito, não se restringe a perdoar $\mathrm{o}$ 
outro por um erro cometido como na última etapa da teoria do reconhecimento de Hegel. Cabe esclarecer melhor esse ponto.

Segundo Flickinger (2011), Hegel considera o reconhecimento social em três etapas. Na primeira, refere-se às paixões que, por anularem muitas vezes a individualidade, não representam um amor legítimo e, assim, dizem respeito a um reconhecimento instável e irrefletido. Na segunda etapa o reconhecimento se dá de modo refletido, mas ainda deficiente: senhor e escravo têm de um reconhecer o estatuto do outro para que ambos se legitimamente mantenham seus papéis. Em outras palavras, o senhor só é senhor porque o escravo o reconhece como tal. Na terceira e última etapa, numa relação dialógica, dar-se-ia o reconhecimento ideal quando um indivíduo é capaz também de perdoar o outro, de tolerar seus desvios em relação àquilo que reconhece ser uma conduta legítima e, assim, admitir o diferente como autêntico, eis o ideal de reconhecimento como relação social (HEGEL apud FLICKINGER, 2011).

Maturana (1998) vai ao encon- tro dessa concepção quando defende que relações sociais são aquelas em que o reconhecimento não depende de um fator hierárquico $e$, nesse sentido, argumenta que as relações de trabalho, por exemplo, não são relações sociais. O amor enquanto reconhecimento do outro independe de qualquer estatuto arbitrário e para Maturana a relação social autêntica é fundada nesse sentimento. Por outro lado, o autor, em certa medida, também transpõe a visão maniqueísta que marca a proposição hegeliana, a de que há um erro a ser perdoado, ou uma transgressão a ser tolerada. Para ele, ao contrário, há apenas divergências. Essas, por sua vez, podem ser lógicas ou ideológicas. São lógicas quando ambos os indivíduos compartilham, por assim dizer, de uma mesma norma e, por equívoco, um deles comete o que, aqui sim, pode-se chamar de erro, uma vez que consistirá num erro também para o transgressor, que o reconhecerá. Esse erro, contudo, só pode ser considerado como tal pelo fato dos dois indivíduos terem, de antemão, admitido uma arbitrariedade, uma convenção, a qual ambos seguirão. Nesse caso, o 
indivíduo que o comete pouco ou nada resistirá em consentir que se equivocou. Exemplificando: se dois estudantes, "X" e "Y", estão a realizar uma equação matemática $e$ em dado momento " $\mathrm{X}$ " extrai como resultado da soma $2+2$, o algarismo 5 , "Y" em geral não precisará de dispendiosos argumentos para convencer " $\mathrm{X}$ " de que cometeu um engano, pois se trata de uma divergência lógica em que ambos estão imbuídos de uma mesma lei, a lei das operações básicas da aritmética.

As divergências, porém, podem também ser ideológicas. Talvez o exemplo mais patente desse tipo de divergências sejam os intermináveis embates políticos em que dois indivíduos de partidos com posições ideológicas opostas argumentam sobre um mesmo tema por horas, alfinetam-se deixando transparecer sua repulsa em relação à posição um do outro e, não raro, tentam, cada um a seu modo, convencer os eleitores de que sua ideologia é mais condizente com os interesses públicos. Tratam-se de duas arbitrariedades diferentes $e$, consequentemente, duas argumentações que seguem caminhos distintos e que dificilmente se encontrarão a não ser em alguns poucos pontos de convergência. Neste caso não há erro de nenhuma das partes, há apenas divergências. E, se "X" e "Y" não admitirem uma mesma norma, jamais haverá auto-reconhecimento do "erro" de qualquer um deles, pois sequer haverá erro substancial e legitimamente reconhecido por ambas as partes. Erro, nessa perspectiva, é só aquilo que pode ser mutuamente reconhecido enquanto tal.

É calcado nessa dinâmica que, o ato de amor a que Maturana (1998) se refere, sequer entenderá a diferença ou a oposição como uma falha a ser perdoada, mas como abertura a uma "conspiração democrática" que proverá indivíduos autônomos e reconhecidos como tais. Aqui se deságua num termo-chave para a educação: autonomia. $\mathrm{O}$ encontro intersubjetivo desde que experienciado sensivelmente é passível justamente de propiciar criações autônomas.

Aliás, a Educação vem vislumbrando como horizonte ideal a formação humana de indivíduos autônomos. Talvez se pudesse de fato eleger esse termo como um dos valores 
essenciais da educação hodierna. Mesmo uma perspectiva mais funcionalista, onde a formação tem o papel de educar o indivíduo para ocupar determinada função na sociedade $e o$ treina para tal função, admite em seu escopo a busca por certo grau de autonomia. O mesmo ocorre com os teóricos liberais ao incluírem como princípios-chave da sua proposição o indivíduo e a liberdade. Desse equacionamento, igualmente se obtém como produto certo nível de autonomia. Não por acaso também, no âmbito do mercado econômico, a principal demanda dos empregadores aos seus aspirantes a funcionários tem sido a proatividade - uma vulgata mercadológica para a qualidade de, autonomamente, ter iniciativa para ação e resolução de problemas.

É claro que, nos exemplos citados, abarcam-se diferentes gradações de autonomia e que a instituição escolar ao longo de sua história se imbuiu de uma série de mecanismos de poder que acabaram por favorecer que uns pudessem auferir mais e outros menos desse valioso fim em si mesmo da práxis educativa. Não obstante, faz-se pertinente analisar com um pouco mais de profundidade esse termo.

Autonomia "significa a capacidade de dar a si mesmo as normas de comportamento e atuação" (FLICKINGER, 2011, p. 08). Portanto, ela pressupõe a presença de outro, ou seja, parte de uma referência intersubjetiva, pois somente no âmbito social faz sentido pensar em normas ou regras de conduta (FLICKINGER, 2011). Nesse sentido, "a busca da mera satisfação imediata dos impulsos vitais deveria dar lugar ao modo refletido de decidir e atuar em consonância com as diretrizes de sua responsabilidade perante seus contemporâneos." (FLICKINGER, 2011, p. 09). Responsabilidade, esta, entendida como "obrigação de respondermos às perguntas para nós colocadas por outrem." (Ibidem).

Essa noção de responsabilidade para com o outro remete diretamente a uma discussão de cunho moral. Pedro Goergen (2007) contextualiza o tema da educação moral na atualidade alertando para o fato de que no cenário contemporâneo a celeridade das mudanças dificulta o ato de retroativamente olhar para o pas- 
sado e analisá-lo para se orientar em relação ao presente e ao futuro. Para o autor isso acaba por desestabilizar a antiga educação moral centrada na autoridade e obediência. Diante dessa nova conjuntura ele lança a seguinte indagação:

Se pelas influências do sistema e de suas instituições o homem se torna egoísta através da multiplicação e exaltação dos interesses privados, como transformar esse indivíduo privado, cujo ideal de felicidade é a satisfação de seus interesses egoísticos, num cidadão preocupado com o bem comum? (GOERGEN, 2007, p.749)

Com base nessa questão Goergen formula uma nova pergunta: "Por que praticar a virtude se ela não conduz à felicidade?" (GOERGEN, 2007, p.749). A partir disso o autor defende uma educação moral consciente dessas particularidades na qual assume papel central o conceito de justiça. Isso no sentido em que Aristóteles definia uma "ação justa": um ponto equilíbrio entre agir e ser tradado com justiça.

Nessa perspectiva, caberá agora pensar como é possível encetar a estabelecer pressupostos éticos para um bem comum a partir da experiência estética intersubjetiva.

\section{Experiência Estética Intersubjetiva como Princípio Ético e Formativo}

"Uma experiência é estética", diz Nadja Hermann, "quando o conceito de natureza racional não satisfaz, mas também não há sossego para a sensibilidade." (2005, p.42). Acerca da experiência do encontro intersubjetivo, pode-se dizer que jamais haverá a possibilidade da pura e simples racionalização. A produção de significados e o redimensionamento da própria apreensão cognitiva de acordo com o rumo da experienciação são possíveis graças à capacidade de perceber o outro, fenômeno que inevitavelmente tem como base os sentidos. Fica claro que estética aqui é entendida, não como ciência do belo, mas do sensível. Sensibilidade que pode ou não apreender o belo. Hermann esclarece que estética diz respeito à "sensação, sensibilidade, percepção pelos sentidos ou conhecimento sensível-sensorial." (HERMANN, 2008, p.18). É nesse sentido que se pretende pensar o encontro intersubjetivo como experiência esté- 
tica que amplia o horizonte formativo dos sujeitos.

Assim, no ato do encontro o remodelamento do sujeito diante do outro se dá numa apreensão sempre em certa medida sensível, mesmo que também racionalizável. Aliás, a sensibilidade, pode-se dizer, compreende a matriz articuladora da própria cognição. A "arte" de aprender sensivelmente com o outro possibilidades de automodelagem artística propicia ao sujeito apreendedor, de um lado o aguçamento e traquejo da sua sensibilidade por meio da experiência do encontro, de outro a sua transformação em alguém renovado, um eu que já é um pouco do outro, ainda que por vezes isso possa ser imperceptível. A propriedade artística dessa experiência formativa reside no seu potencial criativo.

O outro, nesse sentido, é sempre um possível, um viável, um plausível. Não se deve aceitá-lo simplesmente por aceitar, não se trata da uma ética arbitrária ou impositiva. A tolerância é factível, mas sempre limitada. A sua extrapolação vira condescendência ou completa renúncia $e$ abnegação, o seu excesso pode se tornar conivência. O outro é aceitável porque é legítimo, porque sua qualidade de ser o que é no instante em que é cotejado sensivelmente seu ato de ser outro (seu eu) faz sentido, é procedente.

Não obstante, entender que o outro é uma existência plausível significa que ainda que não se compactue ou concorde com ele, ele é possível e por isso se deve respeitá-lo, o que implica também alguma responsabilidade para com ele, pois ele ajuda a constituir um contingente de conjunturas e realidades plausíveis, portanto, problematizáveis e merecedoras de resposta. O outro revela a finitude do eu ao mesmo tempo em que fomenta a reflexão sobre possibilidades de vir a ser. Ele pode ser tudo o que o eu não é, não foi e talvez nunca será. De qualquer modo ele, o outro, constitui, como foi dito, possibilidades de devir. Isso faz, por exemplo, com que o eu se confronte com a impossibilidade de tomar a si mesmo como centro do universo ou como reduto de verdades inflexíveis.

A experiência estética, nesse caminho, pode ser o "modo" de se fazer arranjos com os acontecimentos 
da vida, com as possibilidades de ação, com as convicções, crenças e atitudes. Quesitos, esses, que acabam por confluir também no encontro intersubjetivo. A estética passa a representar a resposta à pergunta "como nos tornamos o que somos" que, não raro, surge a partir da gama de encontros e desencontros com que os sujeitos se deparam.

Desse modo, pode-se pensar a estética como a qualidade das decisões que se toma cada vez que se pensa, age, vive, mas, sobretudo, convive, pois a própria autonomia conceito fortemente entrelaçado à noção de decisão - não faz sentido na vacuidade. Uma vez que a autonomia pressupõe a presença de outrem, a capacidade de decidir sobre normas próprias só faz sentido se existir a partilha da norma e a legitimação da mesma. Ademais, sequer faz sentido a noção de norma fora do âmbito intersubjetivo ou coletivo. O estabelecimento de normas tão somente para si mesmo resumir-se-ia a uma espécie de receituário de como agir de modo utilitário e eficaz para si, mas esboroaria a acepção de norma. Tudo ou nada pode ser "normal" (de acordo com a norma) se não houver o nãoeu para anuir ou discordar daquilo que é norma e (a)normal para o eu, $e$, num segundo momento, possa ou não se tornarem regras para o convívio.

Nesse viés, a experiência estética se articula com a noção de autonomia, pois representa um contingente de possibilidades para agregar valor à qualidade da norma (sempre provisória e passível de aperfeiçoamento). Marcos Villela Pereira salienta que
A atitude estética é uma atitude desinteressada, é uma abertura, uma disponibilidade não tanto para a coisa ou o acontecimento "em si", naquilo que ele tem de consistência, mas para os efeitos que ele produz em mim, na mi- nha percepção, no meu senti- mento. (PEREIRA, 2011, p.114).

Esse desinteresse, ao contrário do que se poderia pensar, refere-se a uma visão, ou, melhor dizendo, a uma imersão, não utilitarista $e$ não necessariamente pré-racionalizada na experiência. Como o próprio autor afirma "a premeditação é da ordem da experiência prática" (PEREIRA, 2011, p.114) e, essa sim, diz respeito à ordem do útil, do cotejamento de Número 21: novembro/2013-abril/2014 
meios para se chegar a fins. O desinteresse, ao invés, dá vazão a possibilidades ainda não pensadas/sentidas e por isso originalmente autoformativas.

Nessa senda também argumenta Goergen quando, parafraseando Theodor Adorno, adverte: "[...] pode-se dizer que estamos vivendo um domínio sem precedentes da razão instrumental e utilitarista (Adorno, 1985), para a qual os fins justificam os meios." (GOERGEN, 2007, p.743). Desgraçadamente, nesse contexto, conceitos como eficiência, eficácia, lucro, domínio e vantagem assumirão posição central nas relações humanas que, dessa maneira, se dão de modo mais interesseiro e utilitarista (GOERGEN, 2007). A alteridade é o meio objetivo e não a contingência para a formação humana que só poderá ser explorada plenamente de modo desinteressado. Desinteresse, esse, que "reside na suspensão dos juízos explicativos que o sujeito poderia proferir ante a coisa ou o acontecimento que vive, de modo que possa colocar-se em uma posição de vulnerabilidade ao seu efeito." (PEREIRA, 2011, p.114).
Dessa maneira, no âmago de uma sociedade capitalista e utilitarista, o grande desafio consiste em subverter a lógica do indivíduo que é levado por uma série de dispositivos a aprender a ser empresário de si, em alguém que buscará ser um artista de si mesmo criando alternativas autônomas para se autoformar e educar, inclusive enquanto sujeito moral. Essa "artisticidade", diferentemente do empreendedorismo, pressupõe o desinteresse e a entrega a uma autoformação intersubjetivamente enriquecedora porque não utilitarista - não orientada por um fim já pensado $e$ almejado de antemão -, mas convidativa à descoberta, pois alargada epistemológica e esteticamente a esfera do improvável ou, como se disse, ao ainda não pensando/sentido.

A busca da expressão estética máxima, por outro lado, sempre se deu por intermédio das artes que, de uns tempos para cá, alinharam-se a uma perspectiva mercadológica. Esse mote foi exaustivamente discutido pelos teóricos da Indústria Cultural. Terry Eagleton, partindo dessa problemática, afirma que mesmo 
Neste contexto rarefeito, a arte ainda poderia falar do humano $e$ do concreto, permitindo-nos um descanso bem-vindo frente aos rigores alienantes dos outros discursos mais especializados, $e$ oferecendo, no coração mesmo desta grande explosão e fragmentação dos saberes, um mundo residualmente comum. (EAGLETON, 1993, p.08).

Jaz aqui novamente o argumento do bem comum. A ideia intrínseca aos pressupostos educacionais de um aprendizado para o convívio. Aprendizado aqui, em contraposição à antiga lógica autoritária e arbitrária apontada por Goergen (2007), que deve se dar por meio de um "descanso bem-vindo" dos tais rigores alienantes a que Eagleton (1993) se refere. Rigores, na óptica do autor, cujas normas oscilam entre a moral autoritária e a tendência a reduzir tudo ao seu teor mercadológico.

Desse modo, seria a abertura a uma convivência intersubjetiva e esteticamente educativa um caminho propício para estabelecer bases éticas? Sob a égide de uma ordem capitalista permeada de influências arbitrárias poderia uma abertura desse cunho contribuir na formação de sujeitos autônomos? Parece que sim. Pois,
[...] se a estética aparece com tanta persistência isto se deve, em parte, a uma certa indeterminação de definição, que nos permite topar com ela num leque variado de questões: liberdade e legalidade, espontaneidade e necessidade, autodeterminação, autonomia, particularidade e universalidade, e tantas outras. (EAGLETON, 1993, p.08).

Convém salientar que essas questões geralmente estão no bojo da discussão sobre ética, ora se relacionando com limites, ora com deveres. Seria ainda desejável que a discussão em torno da ética de algum modo trouxesse à tona a "artisticidade" como via criadora e instituinte de, quiçá, novas fronteiras integradoras de diferenças futuras que por ventura viessem a surgir, porquanto os sujeitos estão em constante vir a ser. Vivenciar a experiência esteticamente é, também, instaurar, mesmo que de forma incipiente, um caminho constante de aprendizado das possibilidades que o outro pode representar. Educar(-se) não é somente informar(se) mas formar(-se) criando também novas possibilidades de ser-estardevir.

Número 21: novembro/2013-abril/2014 
É inegável o modo como, enquanto seres sensíveis, os sujeitos são capazes de captar tão somente uma mínima parte do que os atravessa nas suas experiências. Esses atravessamentos, no entanto, são apreendidos como valorações do que são, de seus modos de ser e estar, de seus juízos de (in)adequação. Ademais, a interpretação dos acontecimentos é invariavelmente influenciada por crivos pré-constituídos no âmbito das experiências ético-estéticas passadas que são assimiladas, registradas e cultivadas a cada experiência perceptiva, de modo que é indispensável, nesse sentido, reconhecer o potencial formativo dos sujeitos como compositores da sua própria existência. Artistas de si que, uma vez amadurecidos enquanto sujeitos experienciadores de encontros estético-formativos em prol também de parâmetros éticos, são paulatinamente mais capazes de atribuir qualidades a própria construção de si. Como bem salienta Javier Sáenz Obregón: "a criação de si mesmo não é um exercício autista." (2007, p.82). $\mathrm{O}$ outro, de qualquer modo, é o parâmetro primeiro para essa criação e o dispositivo motivador da experien- ciação que torna possível o ainda não pensando/sentido. A alteridade representa, portanto, um contingente imensurável de vias de subjetivação $e$ de alternativas de reflexão/ação plausíveis à formação humana em sua dimensão criativa, mas, mais do que isso, diz respeito também à possibilidade de transcendência do instituído e do próprio rompimento com uma perspectiva institucional na direção de uma formação dialógica, negociada e negociável, criativa e autônoma.

\section{Tecendo o Esboço de uma Ética Pla- netária Sensível}

Transpondo essa discussão para o âmbito macropolítico, no contexto das relações globais, cabe elucidar a noção de Terra-Pátria. Para Edgar Morin "a pátria é o mito que ampliou ao conjunto de uma nação os caracteres intrínsecos da solidariedade familiar [das sociedades arcaicas]" (MORIN, 1997, p.99). Para o autor o termo pátria aglutina em uma só palavra a essência de paternidade [obediência/respeito] e de maternidade [aceitação/amor] e, assim, no âmbito global "substitui o cosmopolitismo 
abstrato que ignorava as singularidades culturais e o internacionalismo míope que ignorava a realidade das pátrias. Ela traz à fraternidade a fonte necessária da maternidade. Não há irmãos sem mãe" (MORIN, 1997, p.100). Dessa forma, o autor acredita que tanto o conhecimento complexo como a ideia fundamental de comunidade, sob a forma de ética comunitária, inscritas na psique humana, fundariam uma espécie de religião terrestre, e admite: "Aqui reencontro a própria fonte de minha 'fé': o amorreligião" (MORIN, 1997, p.100).

Subjacentes a esses princípios apontados por Morin (1997), portanto, estão tanto a ideia inevitável do encontro (aqui no âmbito comunitário) quanto certa crença numa espécie de ética sensível colocada pelo autor com certo cunho religioso.

Trata-se, sim, do desígnio de religar-se que, etimologicamente, radica a palavra religião. Religar-se, nesse caso, ao costume de experienciar sensível e em alguma medida instintivamente a arte do encontro para, com isso, criar alternativas de condutas possíveis construindo um repertório de parâmetros experienciais para problematizar a si mesmo constantemente e aprimorar-se enquanto sujeito. Encetar-se-ia, assim, a instaurar uma ética que parta do princípio de que o que realmente se pode fazer por si se expressa mais por meio de um continuum trans-subjetivo do que por uma racionalidade autocentrada. Fazer para si o melhor sob o ponto de vista utilitarista e interesseiro não é fazer por si, mas fazer-se de acordo com uma lógica macroestrutural servindo a determinada ideologia competitiva que quer, na competição, fazer valer a lei do mais forte. $\mathrm{O}$ indivíduo entregue a essa "guerra" perde, assim, tanto a "artisticidade" quanto a autonomia.

O amor-religião em que crê Morin (1997), nesse caso, diz respeito a religar-se ao outro como legítimo outro que, ao ser legítimo, representa um contingente de possibilidades que entretecem o próprio eu. Porque uma vez sendo legítimo e original, o outro não é meramente racionalizável ou utilizável objetivamente (interesseiramente), mas só pode desvelar sua originalidade quando fruído desinteressadamente e de modo a permitir a descoberta por meio da sensibilidade. 
O conhecimento advindo de uma experiência desse cunho se torna mais complexo - pois entretecido, tecido multi-elementarmente de modo conjunto - e vívido, além de reconhecedor do aspecto subjetivo da construção do saber $e$, sobretudo, da construção dos sujeitos em si.

Wolfgang Welsch (1995) argumenta no sentido de defender uma cultura do ponto cego - na qual ao ver algo, também se percebe que se deixa de ver outra coisa -, capaz de reconhecer a diferença, portanto também o outro, por meio da sensibilidade. Assim,

Uma cultura realmente estetizada seria sensível para as diferenças $e$ as desqualificações também no dia-a-dia, digamos, em vistas a outras formas de vida. Sensibilidade desenvolvida percebe princípios desviantes, descobre imperialismos, tem alergia pelas injustiças e exorta a entrar em luta pelos direitos dos oprimidos. A cultura estética seria capaz, deste modo, pelo menos indiretamente, de também contribuir com a cultura política (WELSCH, 1995, p.19).

Logo, a sensibilidade desenvolvida é deveras em grande medida transcendente, pois vai além do esta- belecido ou do perceptivelmente previsível. Ela é capaz de ampliar a percepção daquilo que é contrastante ou reside esconso na experiência, no fenômeno, no encontro. Ela resgata ainda o sentido de responsabilidade para com o outro por meio do olhar autônomo do sujeito sensível capaz de reconhecer o caráter interimplicante daquilo que é experienciado. Por outro lado, uma vez que aglutina $e$ horizontaliza as significações produzidas na intersubjetividade bem como os sujeitos que as produzem, a sensibilidade desenvolvida predispõe os sujeitos a aderirem à conspiração democrática (MATURANA, 1998) e, nesse sentido, parece fornecer uma base substancial à utopia da TerraPátria (MORIN, 1997) enquanto ética agregadora. Uma vez que os indivíduos se tornam sujeitos nesse entretecer intersubjetivo, o propósito do convívio estende-se para o âmbito cognitivo e a sensibilidade ganha força como articuladora do sujeito moral. O significado de conviver ganha um cunho de coautoria dos próprios sujeitos uns em relação aos outros $e$ de todos eles em relação à sociedade. 


\section{Referências}

EAGLETON, Terry. A Ideologia da Estética. Rio de Janeiro: Jorge Zahar, 1993.

FLICKINGER, Hans-Georg. Autonomia e Reconhecimento: dois conceitos-chave na formação. Revista Educação. Porto Alegre: EdiPUCRS, vol.33, n.1, p.07-12, 2011.

GOERGEN, Pedro. Educação Moral Hoje: cenários, perspectivas e perplexidades. Educação \& Sociedade. Campinas, vol. 28, n. 100 - Especial, p.737-762, out. 2007.

HERMANN, Nadja. Estetização do Mundo da Vida e Sensibilização Moral. Educação \& Realidade. Porto Alegre: Faculdade de Educação/UFRGS, v. 30, n. 2, p.3547, 2005.

HERMANN, Nadja. Ética: a aprendizagem da arte de viver. Educação e Sociedade. Campinas: CEDES/Unicamp, v.29 n.102 jan./abr., p.15-32, 2008.

MATURANA, Humberto. Emoções e Linguagem na Educação e na Política. Belo Horizonte: Ed. da UFMG, 1998.

MORIN, Edgar. Meus Demônios. Rio de Janeiro: Bertrand Brasil, 1997.

NIETZSCHE, Friedrich Wilhelm. Humano, Demasiado Humano: um livro para espíritos livres. São Paulo: Companhia das Letras, 2000.

PEREIRA, Marcos Villela. Contribuições para Entender a Experiência Estética. Revista Lusófona de Educação. Lisboa: Universidade Lusófona de Humanidades e Tecnologias, vol. 18, n.18, p.111-123, 2011.

SÁENZ OBREGÓN, Javier. La Escuela como Dispositivo Estético. In: FRIGERIO, Graciela; DIKER, Gabriela (comps.). Educar: (sobre)impresiones estéticas. Buenos Aires: Del Estante Editorial, 2007, p.73-86.

WELSCH, Wolfgang. Estetização e Estetização Profunda ou A Respeito da Atualidade da Estética nos Dias de Hoje. Porto Arte. Porto Alegre: Instituto de Artes/ UFRGS, v.6, n.9, p.7-22, maio, 1995.

Recebido em 26/06/2013

Aprovado em 14/08/2013 